\section{Regulatory T Cells and IL35 in Chronic Hepatitis C Related Cirrhosis and Hepatocellular Carcinoma}

\author{
Esraa H Abd El-Ghani ${ }^{1}$, Noha A Afifi ${ }^{1}$, Maggie A \\ Ibrahim $^{1}$, Asmaa M Zahran ${ }^{2}$, Mohamed A El- \\ Mokhtar $^{1}$, Mohamed A Mekky ${ }^{3}$ and Helal F Hetta ${ }^{1}$
}

\footnotetext{
${ }^{1}$ Department of Medical Microbiology \& Immunology, Faculty of Medicine, Assiut University, Egypt.

${ }^{2}$ Department of Clinical pathology, South Egypt Cancer institute, Assiut University, Assiut, Egypt.

${ }^{3}$ Department of Tropical medicine and Gastroenterology, Faculty of Medicine, Assiut University, Assiut, Egypt.
}

The Egyptian Journal of Immunology Volume 28 (1), 2021: 46-52. www.Ejimmunology.org
Corresponding author: Maggie A Ibrahim, Department of Medical Microbiology \& Immunology, Faculty of Medicine, Assiut University, Assiut, 71515, Egypt.

Email: Maggie.abdallah@hotmail.com.

\begin{abstract}
Regulatory T cells (Tregs) play a fundamental role in maintaining immune homeostasis to balance between the tissue-damaging and protective effects of the immune response. There are strong evidences that Treg cells and their cytokines may play an important role in the induction of tolerance in the liver and progression of HCV infection. Herein, we investigated the frequency of Treg cells and interleukin 35 (IL-35) level in blood and their potential relationship to the various chronic hepatitis C (CHC) complications and outcomes. A total of $36 \mathrm{HCV}$ infected patients subdivided into, $\mathrm{CHC}$ complicated with cirrhosis (HCV LC; $n=18$ ), CHC complicated with hepatocellular carcinoma (HCVHCC; $n=18)$ and apparently healthy control group $(n=18)$ were enrolled in this study. Treg cells percentages were determined by flow cytometric analysis and ELISA was used to measure IL35 serum levels. A significant increase in the frequency of peripheral Tregs and serum IL35 level was found in HCV HCC, and HCV LC groups compared with the control group. The frequency of peripheral Tregs and plasma (IL-35) levels were significantly positively correlated with viral load along with disease progression. We conclude that the higher percentage of Tregs and IL35 level in peripheral blood of HCV HCC and HCV LC groups compared to the control group may suggest their contribution to viral persistence and progression of HCV infection.
\end{abstract}

Keywords: Treg, IL35, HCV, Cirrhosis, HCC.

Date received: 23 January 2021; accepted: 22 April 2021

\section{Introduction}

Infection with hepatitis $\mathrm{C}$ virus (HCV) is a major cause of chronic liver disease. ${ }^{1-4}$ The World Health Organization (WHO) estimates that at least 71 million people are persistently infected with HCV and are at risk for serious liver diseases, including potentially fatal hepatic cirrhosis and hepatocellular carcinoma (HCC). ${ }^{5,6}$
Surviving an infection requires the generation of a controlled immune response in the host that recognizes and eliminates the invading pathogen while limiting the collateral damage to self-tissues that can result from an exuberant immune response. At the same time, most microorganisms have to avoid elimination by the host immune response to guarantee their successful transmission. So during an infection, 
immune regulation can arise as a result of the host response to the infectious process in a bid to maintain or restore a homeostatic environment and/or it can be actively induced by the pathogen to promote pathogen survival. ${ }^{7}$

Treg cells, a subtype of T-cells, play a fundamental role in maintaining immune homeostasis to balance between the tissuedamaging and protective effects of the immune response. Treg cells are characterized by the expression of the Forkhead box protein P3 (FoxP3) transcription factor in the nucleus and is generally accepted as the best single marker for Treg cells. ${ }^{8-12}$

There is strong evidence that Treg cells and their cytokines may play an important role in the induction of tolerance in the liver ${ }^{13-16}$. In some circumstances, the regulation exerted by Treg cells is excessive and prevents the establishment of protective immune responses, whereas in other circumstances, this control is not sufficient to prevent immunopathology. At both extremes, manipulation of Treg cells could offer therapeutic potential. ${ }^{7}$

Interleukin 35 (IL-35), a newly identified member of the IL-12 cytokine family, has been reported to suppress inflammation and induce immunotolerance. Activated peripheral blood mononuclear cell (PBMC)- derived human Tregs have been shown to express and secrete large amounts of IL35, which contributes significantly to the suppressive capacity of Tregs in an IL35dependent manner ${ }^{17}$. Additionally, human Tregderived IL35 is required for the conversion of human conventional Treg cells into iTr35 cells, which then promote the generation of more iTr35 cells via IL35 secretion, resulting in infectious tolerance. ${ }^{18}$ In this study, we evaluated the role of peripheral Treg cells in $\mathrm{HCV}$ infection by investigating the frequency of Treg cells and IL35 serum level to determine their relationship to viral persistence and $\mathrm{HCV}$ pathogenesis.

\section{Patients and Methods}

\section{Patients' recruitment}

A hospital-based cross-sectional descriptive study was conducted to evaluate the role of Treg cells and IL35 in chronic hepatitis C (CHC) patients. All participants were recruited from Assiut Liver Institute for Treatment of Hepatitis
C Virus and Assiut University Hospitals outpatient clinics, Assiut, Egypt, between December 2017 to September 2018.

Inclusion criteria for the patients were positive for HCV antibodies by ELISA and HCV-RNA by real-time polymerase chain reaction (RT-PCR) without selection by race, age, or gender. Exclusion criteria were pregnancy, history of Schistosoma infection, inflammatory bowel diseases (IBDs) or suspected IBD, autoimmune diseases including rheumatoid arthritis, and any patients on systemic immunomodulators.

Patients were grouped into three groups; CHC complicated with cirrhosis (HCV LC; $n=18$ ), $\mathrm{CHC}$ complicated with hepatocellular carcinoma ( HCV HCC; $n=18$ ) and an apparently healthy control group $(n=18)$. Controls were attending the blood bank of Assiut University Hospital during the study period. They were negative for known serologic markers of hepatitis ( $B$ \& C) including hepatitis $B$ surface antigen and antibodies to Hepatitis $C$ virus. Two milliliters of blood were drawn from each subject.

\section{Examination of the frequency of Treg cells}

A fluorescence-activated cell sorter (FACSCalibur, Becton Dickinson, CA, USA) flow cytometry was used for phenotypic analysis of PBMC in whole blood samples using a set of fluorochrome-labelled monoclonal antibodies against Treg surface and intracellular markers. Antibodies from Alexa Flour were used, FITC conjugated CD25 (Anti human CD25/IL-2 R alpha Alexa Flour, R\&D, USA, Cat No. FAB1020G-100), APC conjugated Foxp3 (Anti human Foxp3 Alexa Flour 488, R\&D, USA, Cat No. IC8214G-100) and Per-CP conjugated CD4 (Anti human CD4 Alexa Flour, R\&D, USA, Cat No FAB3791C-100). The Data were analyzed as \% frequency of Treg cells gated from CD4+ CD25+ ${ }^{\text {high }}$ as shown in Figure 1.

\section{IL-35 measurement}

IL- 35 serum concentration was measured for all participants using ELISA kit (Glory Science CO., Ltd, USA, Cat No \#:99569) according to the manufacturer's protocol.

\section{Statistical analysis}

IBM SPSS 20.0 software was used for all analyses. The Kolmogorov-Smirnov test was used for testing normality and homogeneity variances prior to any statistical analysis. 
Number and percent ( $N$, \%) were used to describe categorical variables while mean and standard deviation (Mean, SD, Median) for continuous variables. For comparison, Chisquare was used for categorical variables, t-test for continuous variables t-test and Kruskal Wallis test for parametric data and nonparametric data and a two-tailed $P<0.05$ was considered statistically significant. Correlation was done using Pearson test.
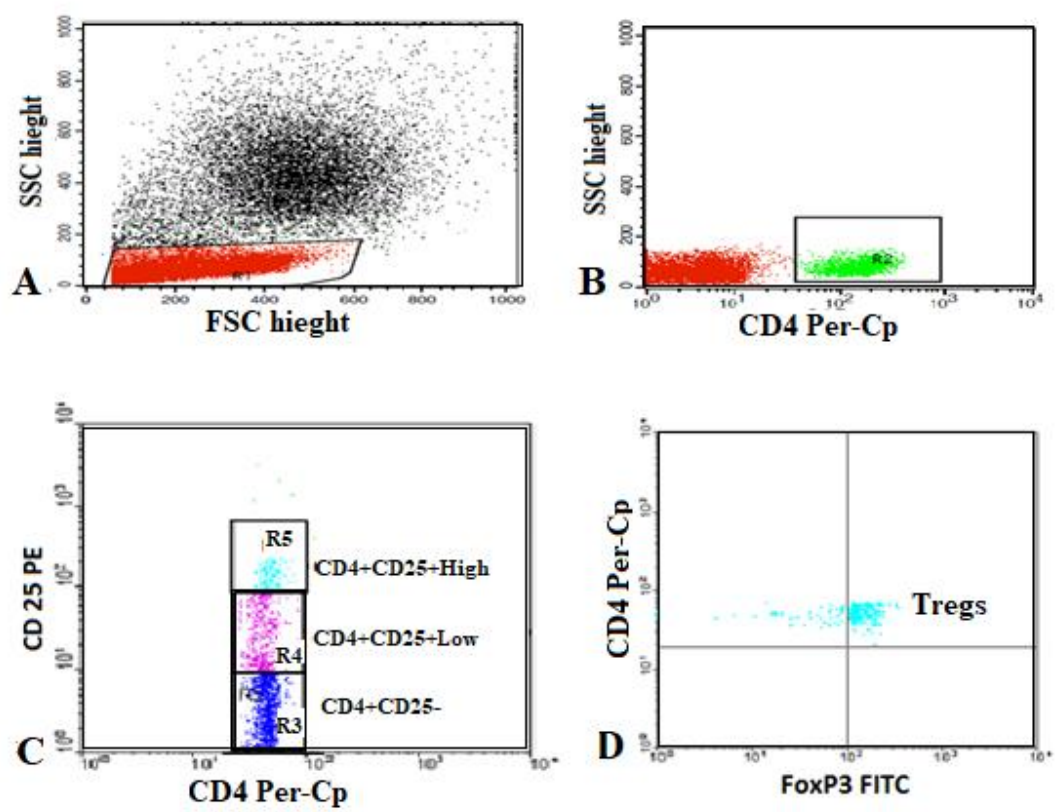

Figure 1. Flow cytometric detection of T- Iymphocytes and regulatory T cells. A: Forward and side scatter histogram was used to define the lymphocytes population (R1). B: The expression of CD4 ${ }^{+}$was assessed on lymphocytes population and $\mathrm{CD} 4^{+} \mathrm{T}$ cells gated. $\mathrm{C}$ : Then the expression of $\mathrm{CD} 25$ on $\mathrm{CD} 4^{+} \mathrm{T}$ cells was detected and different gates were drown to define $\mathrm{CD} 4^{+} \mathrm{CD} 25^{-}$cells (R3), $\mathrm{CD} 4^{+} \mathrm{CD} 25^{\text {+low }}$ cells (R4), and $\mathrm{CD} 4^{+} \mathrm{CD} 25^{+\mathrm{High}}$ cells (R5). D: The percentage of $\mathrm{CD} 4^{+} \mathrm{CD} 25^{\text {thigh }} \mathrm{FoxP}^{+}$cells (Tregs) on $\mathrm{CD} 4^{+} \mathrm{T}$ cells was determined.

\section{Results}

\section{Characterization of the enrolled subjects}

Table 1 summarize the demographic and laboratory data of the enrolled subjects. The ages of HCV HCC patients were the highest (Mean \pm SD; $61.94 \pm 4.37$ ) followed by HCV LC patients (44.78 \pm 5.73 ) and lastly controls (32 \pm 10.2). Regarding sex predominance in patients, $\mathrm{HCV}$ predominated in males more than females in HCV LC and in HCV HCC (Male: Female \%; 66.7:33.3 \%; 88.9: $11.1 \%$, respectively). However, in the control group, females were more than males (Female: Male; 55.6\%: 44.4\%).

\section{Biochemical and laboratory data of patients} and controls

Table 1. Demographic and biochemical data of different research groups.

\begin{tabular}{lccc}
\hline HCV LC $(n=18)$ & HCV HCC $(n=18)$ & Control $(n=18)$ \\
Mean $\pm S D$ & Mean $\pm S D$ & Mean $\pm S D$ \\
\hline Age & $44.78 \pm 5.73$ & $61.94 \pm 4.37$ & $32 \pm 10.02$ \\
\hline
\end{tabular}

These data were obtained from the patient's regular hospital data on admission. For the control group, data were obtained from the blood bank of Assiut University Hospital as routine tests before donating blood. Biochemical and laboratory data of patients and controls were included to determine whether there is a relation between any of them (as indicator for disease progression) and Tregs or IL-35. In HCV HCC and HCV LC patient groups, the mean ALT, AST, total bilirubin and ALP levels were increased. 


\begin{tabular}{lccc}
\hline $\begin{array}{l}\text { Sex } \\
\text { (Male: Female, n) } \\
\text { (Male: Female; \%) }\end{array}$ & $12: 6$ & $16: 2$ & $8: 10$ \\
\hline PCR IU/ml & $66.7: 33.3 \%$ & $88.9: 11.1 \%$ & $44.4: 55.6 \%$ \\
\hline Total Bilirubin $\mathrm{mg} / \mathrm{dl}$ & $4.98 \pm 1.65 \times 10^{5}$ & $6.13 \pm 1.15 \times 10^{5}$ & $0 \pm 0$ \\
\hline Direct Bilirubin $\mathrm{mg} / \mathrm{dl}$ & $2.52 \pm 1.03$ & $2.49 \pm 1.23$ & $0.36 \pm 0.27$ \\
\hline Total Protein g/dl & $1.89 \pm 1.2$ & $7.78 \pm 5.46$ & $0.33 \pm 0.16$ \\
\hline Albumin; g/dl & $5.69 \pm 1.34$ & $5.17 \pm 1.13$ & $6.99 \pm 0.45$ \\
\hline A/G & $2.2 \pm 0.82$ & $2.35 \pm 0.82$ & $3.52 \pm 0.32$ \\
\hline AST U/L & $1.35 \pm 0.68$ & $1.6 \pm 0.72$ & $0.71 \pm 0.31$ \\
\hline ALT U/L & $61.94 \pm 30.63$ & $118.67 \pm 63.4$ & $12.56 \pm 1.54$ \\
\hline ALP U/L & $44.28 \pm 17.83$ & $183.5 \pm 248.49$ & $13.28 \pm 2.05$ \\
\hline Urea mg/dL & $107.06 \pm 40.55$ & $167.33 \pm 41.23$ & $53.78 \pm 12.55$ \\
\hline Creatinine mg/dl & $10.4 \pm 6.81$ & $10.87 \pm 6.49$ & $13 \pm 1.81$ \\
\hline Prothrombin time sec & $1.36 \pm 1.28$ & $1.13 \pm 0.62$ & $0.77 \pm 0.22$ \\
\hline Prothrombin conc & $16.38 \pm 4.57$ & $17.53 \pm 4.61$ & $11.87 \pm 1.05$ \\
\hline INR & $48.31 \pm 17.84$ & $51.81 \pm 15.32$ & $96.37 \pm 9.73$ \\
\hline n: number, ALT: alanine aminotransferase, AST: aspartate aminotransferase, ALP: alkaline phosphatase, INR: International \\
Normalization Ratio.
\end{tabular}

\section{Characterization of peripheral Treg cells}

The frequency of Treg cells in the study groups is presented in Table 2. The mean of CD4 ${ }^{+} \mathrm{CD} 25^{+}$high Foxp $^{+}$Treg cells percentage (from $\mathrm{CD} 4^{+} \mathrm{CD} 25^{+}$high $\mathrm{T}$ cells) was the highest in peripheral blood of HCV HCC group (96.96 \pm 4.22\%) followed by HCV LC group (90.9 $\pm 5.49 \%)$ and lastly the control group (73.53 $\pm 20.68 \%)$.
There was a significant difference in Treg cells percentage between HCV HCC and HCV LC (HCV HCC > HCV LC, $P<0.002$ ). There was a significant difference in Treg cells percentage between the controls and HCV LC (HCV LC > Controls, $P=0.008)$, and between HCV HCC and the controls (HCV HCC > Controls, $P<0.001$ ).

Table 2. Multi-comparison of regulatory T cells percentage between the studied groups.

\begin{tabular}{lccc} 
Treg cells\% (Mean \pm SD) & HCV LC & HCV HCC & Control \\
& $(90.9 \pm 5.49)$ & $(96.96 \pm 4.22)$ & $(73.53 \pm 20.68)$ \\
\hline HCV LC & - & & \\
\hline HCV HCC & $P 1=0.002$ & - & \\
\hline Control & $P 2=0.008$ & $P 3<0.001$ & - \\
\hline Kros & & &
\end{tabular}

Kruskal Wallis test, $P<0.05$ indicates significant statistical difference.

Correlation between Treg cells percentage and laboratory data in studied groups

In HCV HCC group, there was a significant negative correlation between Treg cells percentage and albumin level $(R=-0.552, P=$ 0.018 ) as shown in Figure 2. There was no correlation with other laboratory parameters.

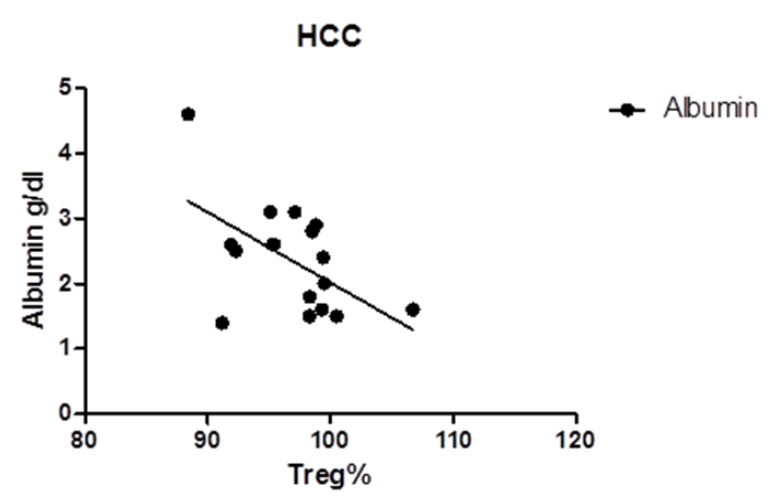


Figure 2. Correlation between Treg cells percentage and albumin level in HCV HCC

\section{Comparison in serum IL35 levels between groups}

The mean serum level of IL-35 concentration was significantly higher in HCV HCC group (mean \pm SD: $64.86 \pm 30.84$ ) and the HCV LC group $(52.5 \pm 15.14)$ than the control group

Table 3. Comparison in serum IL35 levels between groups

\begin{tabular}{lccc}
\hline IL-35 pg./ml & HCV LC & HCV HCC & Control \\
\hline HCV LC & $(52.5 \pm 15.14)$ & $(64.86 \pm 30.84)$ & $(19.11 \pm 4.62)$ \\
\hline HCV HCC & - & & \\
\hline Control & $P 1=0.308$ & - & - \\
\hline
\end{tabular}

(19.11 \pm 4.62). Serum level of IL35 was significantly higher in the HCV LC group vs. the control group (HCV LC > control, $P=0.001$ ) and in the HCV HCC group vs. the control group (HCV HCC > control, $P<0.001$ ). However, there was no significant difference between serum level of IL35 in the HCV HCC group vs. the group HCV LC $(P=0.308)$, as shown in Table 3.

Kruskal Wallis test.

$P<0.05$ indicates significant difference

Correlation between the percentage of Treg cells and IL35 serum level in all research groups

No correlation was found between the percentage of Treg cells and IL35 serum level in all research groups.

\section{Discussion}

In the present study, we investigated the frequency of Treg cells and IL35 level and their potential relationship to the various $\mathrm{CHC}$ complications and outcomes. We found that the highest percentage of Treg cells was seen in the peripheral blood of patients with HCV HCC group when compared to other groups included in the study. These findings were consistent with those of Yoshizawa et al., 2010 who reported that the highest percentage of Treg cells in the total CD4+T cell population was seen in the peripheral blood of patients with $\mathrm{HCC}^{19}$ Also, Nafady et al., 2018 and Zahran et al., 2019 found that the frequency of CD4+CD25high+ T regulatory (Treg) cells increased in HCV-infected patients, compared with those in control, and FOXP3 was upregulated. ${ }^{20,21}$

Most of prior studies focused on the wellknown cytokines secreted by Treg cells such as IL10 and TGF $\beta$, but in our study, we tried to determine the role of a novel downregulatory cytokine (IL35) in various stages of chronic HCV infection. We examined the frequency of Treg cells and IL35 concentration in peripheral blood of different stages of chronically infected HCV.

Our results showed that the highest percentage of Treg cells within the $\mathrm{CD} 4^{+} \mathrm{CD} 25^{\text {high }}$ cell population was seen in the peripheral blood of patients with HCV HCC group followed by HCV LC group and lastly by the control group. These findings were consistent with those of Yoshizawa et al., 2010 who reported that the highest percentage of Treg cells in the total $\mathrm{CD} 4+\mathrm{T}$ cell population was seen in the peripheral blood of patients with HCC $(6.80 \pm$ $0.30 \%)$ followed by HCV LC $(6.10 \pm 0.28 \%)$ then Naïve $\mathrm{CHC}(5.88 \pm 0.19 \%)$, and lastly the controls $(5.13 \pm 0.25 \%)$. Also, more recent studies are concordant with our findings as with those of Nafady et al., 2018 who stated that the frequency of $\mathrm{CD} 4+\mathrm{CD} 25$ high $+\mathrm{T}$ regulatory (Treg) cells increased in HCV-infected patients, compared with those in control, and FOXP3 was upregulated within them ${ }^{20}$ and Zahran et al., 2019 who reported a higher Treg percentage in HCC than controls. ${ }^{21}$ There was a significant difference between HCV HCC and HCV LC groups $(P<0.001)$, consistent with the findings reported by Yoshizawa et al., 2010. We found that there was no significant difference between HCV LC and CHC which was consistent with the findings reported by Yoshizawa et al., 
2010 who stated that the proportion of Treg cells did not increase in HCV LC compared with $\mathrm{CHC}^{19}$

Herein, we measured the serum IL-35 level by indirect ELISA and we found that serum IL-35 concentration was higher in HCV HCC group and HCV LC group than the control group. Consistent with our results are those reported by Liu et al., 2017 and Hu et al., 2018. However, in these studies the expression of IL35 at the protein level was detected with immunehistochemistry $(\mathrm{IHC}) .{ }^{22,23}$

Unfortunately, in our research, no correlation was found between Treg cells percentage and IL35 serum concentration in all research groups. Such observation may be due to the small sample size and the lack of measuring IL35 from activated Tregs instead of serum concentration which represent a limitation of our study.

In conclusion, Treg cells and IL 35 appear to have association with the hepatic pathologic damage, HCV pathogenesis and complications that suggests a strong linkage between Treg cell populations and hepatic insult.

\section{Author Contributions}

NA, Main Supervisor, EH, MM, Acquisition of data, $\mathrm{EH}, \mathrm{MA}, \mathrm{AZ}, \mathrm{MM}$, Analysis and interpretation of data, $\mathrm{EH}$ Drafting of manuscript, $\mathrm{NA}, \mathrm{MA}, \mathrm{HH}$, Critical revision.

\section{Declaration of Conflicting Interests}

The author(s) declared no potential conflicts of interest with respect to the research, authorship, and/or publication of this article.

\section{Funding}

This work was funded by Faculty of Medicine Grant Office, Assiut University, Grant number: 2017/03/29020-R1

\section{Ethical approval}

The study protocol was reviewed and approved by the Committee of Medical Ethics, Faculty of Medicine, Assiut University (19/4/2017).

\section{Informed consent}

A signed consent form was obtained from each study participant.

\section{References}

1. Abd Ellah NH, Tawfeek HM, John J, et al. (2019) Nanomedicine as a future therapeutic approach for Hepatitis C virus. Nanomedicine, 14(11):1471-1491.

2. Mekky MA, Abdel-Malek MO, Osman HA, et al. (2019) Efficacy of ombitasvir/paritaprevir/ ritonavir/ribavirin in management of HCV genotype 4 and end-stage kidney disease. Clinics and research in hepatology and gastroenterology; 43(1):82-87.

3. Mekky MA, Sayed HI, Abdelmalek MO, et al. (2019) Prevalence and predictors of occult hepatitis $C$ virus infection among Egyptian patients who achieved sustained virologic response to sofosbuvir/daclatasvir therapy: a multi-center study. Infection and drug resistance; 12:273.

4. Shata MTM, Abdel-Hameed EA, Hetta HF, et al. (2013) Immune activation in HIV/HCV-infected patients is associated with low-level expression of liver expressed antimicrobial peptide-2 (LEAP-2). Journal of clinical pathology; 66(11):967-975.

5. Bartenschlager R, Baumert TF, Bukh J, et al. (2018) Critical challenges and emerging opportunities in hepatitis $C$ virus research in an era of potent antiviral therapy: Considerations for scientists and funding agencies. Virus research; 248:53-62.

6. Hetta HF, Mekky MA, Khalil NK, et al. (2016) Extrahepatic infection of hepatitis $C$ virus in the colon tissue and its relationship with hepatitis $C$ virus pathogenesis. Journal of medical microbiology; 65(8):703.

7. Belkaid Y. Regulatory $T$ cells and infection: $a$ dangerous necessity. Nature Reviews Immunology; 7(11):875.

8. Keynan Y, Card CM, McLaren PJ, et al. (2008) The role of regulatory $T$ cells in chronic and acute viral infections. Clinical infectious diseases: an official publication of the Infectious Diseases Society of America; 46(7):1046-1052.

9. Sakaguchi S, Yamaguchi T, Nomura T, et al. (2008) Regulatory $\mathrm{T}$ cells and immune tolerance. Cell; 133(5):775-787.

10. Magg T, Mannert J, Ellwart JW, Schmid I, Albert $\mathrm{MH}$. Subcellular localization of FOXP3 in human regulatory and nonregulatory $\mathrm{T}$ cells. European journal of immunology; 42(6):1627-1638.

11. Sturm N, Thelu MA, Camous $X$, et al. (2010) Characterization and role of intra-hepatic regulatory T cells in chronic hepatitis C pathogenesis. J Hepatol; 53(1):25-35.

12. Zahran AM, Nafady-Hego H, Mansor SG, et al. (2019) Increased frequency and FOXP3 expression of human $\mathrm{CD} 8+\mathrm{CD} 25 \mathrm{High}+\mathrm{T}$ lymphocytes and its relation to CD4 regulatory $T$ cells in patients with hepatocellular carcinoma. Human immunology; 80(7):510-516. 
13. Adams DH, Eksteen B, Curbishley SM. (2008) Immunology of the gut and liver: a love/hate relationship. Gut; 57(6):838-848.

14. Hetta HF, Mehta MJ, Shata MTM. (2014) Gut immune response in the presence of hepatitis $C$ virus infection. World Journal of Immunology; 4(2):52-62.

15. Hetta HF, Mekky MA, Khalil NK, et al. (2015) Association of colonic regulatory $T$ cells with hepatitis $\mathrm{C}$ virus pathogenesis and liver pathology. Journal of gastroenterology and hepatology; 30(10):1543-1551.

16. Mehta M, Hetta HF, Abdel-Hameed EA, et al. (2016) Association between IL28b rs12979860 single nucleotide polymorphism and the frequency of colonic T reg in chronically HCV-infected patients. Archives of virology; 161(11):3161-3169.

17. Lauren W. Collison, Creg J. Workman, et al. (2007) The inhibitory cytokine IL-35 contributes to regulatory T-cell function. 450: 566-569.

18. Chaturvedi V, Collison LW, Guy CS, et al. (2011) Cutting edge: human regulatory $\mathrm{T}$ cells require IL-35 to mediate suppression and infectious tolerance. The Journal of Immunology; 186(12):6661-6666.
19. Yoshizawa K, Abe H, Kubo $\mathrm{Y}$, et al. (2010) Expansion of CD4(+)CD25(+)FoxP3(+) regulatory $\mathrm{T}$ cells in hepatitis $\mathrm{C}$ virus-related chronic hepatitis, cirrhosis and hepatocellular carcinoma. Hepatology research: the official journal of the Japan Society of Hepatology; 40(2):179-187.

20. Nafady A, Nafady-Hego H, Abdelwahab NM, et al. (2018) Peripheral lymphocytes analyses in children with chronic hepatitis $\mathrm{C}$ virus infection. Eur J Clin Invest; 48(10):e13004.

21. Zahran AM, Nafady-Hego H, Mansor SG, et al. (2019) Increased frequency and FOXP3 expression of human CD8+ CD25High+ lymphocytes and its relation to CD4 $\mathrm{T}$ regulatory cells in patients with hepatocellular carcinoma. Human immunology.

22. Liu S, Zhang Q, Shao X, et al. (2017) An immunosuppressive function of interleukin-35 in chronic hepatitis $\mathrm{C}$ virus infection. Int Immunopharmacol; 50:87-94.

23. Hu M, Zhang J, Zhu J, et al. (2018) Prognostic signifcance of IL35 expression in human hepatocellular carcinoma. International Journal of Clinical And Experimental Pathology. 11(9):46954702. 